\title{
Realismo mágico y real maravilloso: modelos interpretativos para la historia cultural de América Latina
}

\section{Magical Realism and Marvelous Real: Interpretative Models for the Latin America Cultural History} Antonio Álvarez Pitaluga*

\begin{abstract}
Resumen: se propone un acercamiento histórico a las categorías literarias, realismo mágico y real maravilloso, mediante un análisis de sus potencialidades como modelos interpretativos para la historia cultural de Latinoamérica. Se demuestra, además, que sus más reconocidos representantes, Miguel Ángel Asturias y Alejo Carpentier, estructuraron dichas aportaciones desde una perspectiva historicista como modelos transdiciplinarios para la comprensión cultural de América Latina.
\end{abstract}

Palabras claves: historia; cultura; literatura; novela; escritura; América Latina.

\begin{abstract}
The article proposes a historical approach to literary categories, magical realism and Marvelous Real. Their potentialities are analyzed as interpretive models for the cultural history of Latin America. It is intended to demonstrate that its most recognized representatives, Miguel Ángel Asturias and Alejo Carpentier, structured these contributions from a historicist perspective as trans-disciplinary models for the cultural compression of Latin America.
\end{abstract}

Keywords: History; Culture; Literature; Novel; Writing; Latin America.

\section{Un lugar en la historia}

Qué lugar ocupa América Latina en la historia universal? Inspirada en una similar inquietud, formulada desde el quehacer intelectual del proyecto grupal más importante de la primera mitad del siglo XX en Cuba, el grupo

Fecha de recepción: 06/08/2019 - Fecha de aceptación: 28/08/2019

Cubano. Doctor en Ciencias Históricas por la Universidad de La Habana (UH), Cuba. Doctorado Académico por la Universidad de Costa Rica (UCR), Costa Rica. Académico de la Universidad Nacional (UNA), Costa Rica y del Doctorado en Estudios de la Sociedad y la Cultura de la UCR. Correo electrónico: antonio.alvarez.pitaluga@una.cr. 
Orígenes, la dimensión informativa de una probable respuesta a pregunta tan abarcadora, sería el equivalente a la amalgama de varios discursos históricos. Estos se han producido desde los intersticios de la universalidad de la historia y las civilizaciones humanas en los últimos cinco siglos. No obstante, a pesar de los más de quinientos años transcurridos a partir de la forzosa incorporación de América al entramado de la historia universal, todavía una respuesta convincente sigue siendo una ecuación exegética de difícil comprensión para la persona occidental, tanto europea como americana.

$\mathrm{Y}$ es que no pocas interpretaciones socioculturales de América Latina se han articulado desde tradiciones ideológicas e historiográficas asociadas directamente al poder de los vencedores, o sea, a los colonizadores europeos, los dominadores de matriz occidental. Sus visiones, lógicas y racionalidades, fueron mayormente, las triunfadoras durante más de cinco centurias, dando vida a una predominante racionalidad histórica occidental para ver y entender a América Latina. Tan preponderante ha sido, que a finales del siglo XX, todavía se prefería esperar a que un europeo nos explicase cómo se produjo la colonización cultural del continente, cuando más de tres décadas atrás ya los latinoamericanos la habían revelado, sin descontar otras miradas primigenias, como las de José Martí (1853-1895) con su emblemático texto «Nuestra América», ${ }^{1}$ de 1891.

Así, en 1982 Tzvetan Todorov desplegó su reflexión en torno a La conquista de América. La cuestión del otro, ${ }^{2}$ sobre la imposición colonizadora desde el lenguaje, los signos, los símbolos y la religión, es decir, la dominación cultural como fórmula de colonización en América. Sin embargo, treinta y seis años atrás, en 1946, el escritor latinoamericano Alejo Carpentier ya había examinado semejante suceso en su obra La música en Cuba, al decir que, en la conquista europea de América: «Terminada la lucha de los cuerpos, iniciábase la lucha de los signos». ${ }^{3}$

Desde tal lógica europeizante, el continente es aún hoy visto como tierra rescatada de la barbarie, conjunto de paraísos exóticos que han sido occidentalizados con mayor o menor éxito, ${ }^{4}$ lugar de feroces enfrentamientos en aras de civilizar y educar al estilo occidental; también, espacio de adoctrinamiento cultural. ${ }^{5}$ Uno de los resultados culturales más complejos de esa occidentalización

1 José Martí, «Nuestra América», La Revista Ilustrada de Nueva York (10 de enero de 1891), http://bibliotecavirtual.clacso.org.ar/ar/libros/osal/osal27/14Marti.pdf.

2 Tzvetan Todorov, La conquista de América. La cuestión del otro (Ciudad de México, México: Siglo Veintiuno Editores, 1998).

3 Alejo Carpentier, La música en Cuba (Ciudad de México, México: Fondo de Cultura Económica, 1946).

4 Esteban Barboza Núñez, Litorales imaginados, dominios construidos: desarrollo turístico de sol y playa y discurso colonial en Guanacaste (Tesis doctoral Universidad Nacional de Costa Rica, Costa Rica, 2019).

5 Aquellas realidades históricas e ideológicas pueden ser vista de manera sintética en las películas conmemorativas por el quinto centenario del "descubrimiento" de América, producida a finales del siglo pasado: 1492: la conquista del paraiso (EE. UU.: Paramount Pictures, 1992); La controversia de Valladolid (Francia: FR3, 1991). 
colonizadora es el hecho de que los propios latinoamericanos nos sentimos parte esencial de Occidente, y por tanto, vemos y entendemos nuestra realidad desde la lógica y la temporalidad occidental, a pesar de reconocer a un mismo tiempo nuestras raíces indígenas, africanas y de otras latitudes del mundo. En consonancia, asumimos la multiculturalidad de los últimos cinco siglos, pero no tanto así, la transculturalidad y los sincretismos de nuestras sociedades, bases de nuestras actuales identidades nacionales. ${ }^{6} \mathrm{Al}$ igual que ocurre en la relación dominador/ dominado, admitimos ser, consciente o inconscientemente, el otro de Todorov, sin significar esto su plena comprensión cultural.

Las raíces de tal asunción mental e ideológica tienen extensiones en el pensamiento y en las mentalidades excluyentes de varias ciudadanías latinoamericanas, y tanto es así, que hoy se dibujan como paradojas de la historia cuando en la propia Europa existen sectores sociales, academias e intelectuales que reconocen las mezclas y los aportes culturales de otras civilizaciones y culturas llegadas a sus tierras.

No pocos escritores latinoamericanos contribuyeron a la construcción mental y cultural de nuestras occidentalizaciones sociales, durante los últimos doscientos años de historia, desde el comienzo del proceso independentista, de 1810-1824, pasando por la formación de los Estados Nacionales, 1830-1870, hasta la deformante inserción de la región en la órbita del capitalismo mundial, desde buena parte del siglo XIX y la primera del XX. Tal vez, Domingo Sarmiento con su dicotomía, civilización y barbarie, ${ }^{7}$ fue uno de los iniciadores de esa construcción occidentalizadora de Latinoamérica, elaborada por sus propios intelectuales.

Al extrapolar esquemas ideológicos y raciales, sistemas de relaciones sociales y parámetros escriturales de la literatura europea, varios escritores latinoamericanos, voluntaria o involuntariamente, han definido una visión de América Latina con base en la lógica occidental. Esta se ha embonado con la propia comprensión de América desde Europa, la misma que insiste en vernos y estudiarnos, desde su raciocinio histórico de evolución lineal a través de periodos históricos o formaciones socioeconómicas sucesivas. Desde dicha racionalidad histórica se establecieron igualdades, desigualdades o similitudes entre Europa y América para entender el devenir sociocultural de la última; así, por ejemplo, el transcurso y el ritmo del tiempo histórico americano son semejantes al europeo. De igual modo para casi todas las élites tradicionales en el poder, no

6 Como ya se ha explicado en el cuerpo del texto, el concepto de transculturación de Fernando Ortiz da cuentas de un complejo procesos de sincretismos culturales en América Latina desde los inicios de su colonización. A partir de él, y para una mayor afinidad comprensiva de sus procesos derivados, estos son nominados aquí desde esa matriz que les dio orígenes; así, transculturalidad identifica la imagen del conjunto de procesos culturales de una nación, región o del continente; por su parte, transculturado, nos indica un producto cultural mezclado, sincretizado.

7 Domingo Sarmiento, Civilización i barbarie. Vida de Juan Faustino Quiroga (Santiago de Chile, Chile: Imprenta el Progreso, 1845). 
pocos procesos de formaciones nacionales, identidades culturales o el desarrollo de grupos y clases sociales latinoamericanos, se explican desde una perspectiva europea y occidental. Por casi cuatro siglos Europa y el mundo occidental, de matrices grecolatinos, se convirtieron no solo en referentes colonizadores y culturales del subcontinente, sino, además, en lógicas explicativas de la evolución y la comprensión de América Latina desde los inicios de la modernidad hasta los albores del siglo XX.

\section{Desilusión europea y nacionalismos latinoamericanos}

El fin de la Bella Época (1871-1914), generó a principios del siglo XX, una profunda crisis doctrinal del liberalismo capitalista occidental y sus valores culturales. Parafraseando dos títulos de la producción historiográfica de Eric Hobsbawm, el ocaso de la era de los imperios, dio paso a su corto siglo XX. ${ }^{8}$ La decepción por los desastres y los resultados de la Primera Guerra Mundial se hicieron generacionales y de honduras internacionales. En más de un sentido, Occidente y sus valores dejaron de ser un paradigma cultural para diversos grupos de intelectuales desde las dos orillas del Atlántico. Poco a poco Europa comenzó a ser vista como una región geográfica y entidad histórica, sin el protagonismo cultural de otrora, como lo explicó en 1918 y 1923 Oswald Spengler en su obra en dos tomos, La decadencia de Occidente. ${ }^{9}$ Desde aquellos años el Viejo Mundo enfrentaría un declive cultural, como otras regiones, épocas o civilizaciones lo habían arrostrado después de un previo esplendor. Ese fue el caso de la civilización árabe entre los siglos VII-XIV, cuando fue importante epicentro de cultura universal, mientras Europa respiraba siglos de periferia.

En América Latina la crisis doctrinal de Occidente y el estallido de la Revolución Rusa jalonaron más aún los efectos y las consecuencias del hecho que abrió el siglo XX latinoamericano: la Revolución Mexicana de 1910. El conjunto de sus acontecimientos produjo fuertes expresiones nacionalistas, que todavía hoy son palpables en la sociedad y la cultura mexicana, y que incidieron por aquel entonces en una mirada crítica sobre distintos aspectos culturales de corte occidental en otros países de América del sur.

El historiador latinoamericanista Sergio Guerra ha visto el auge de los escritores de la tierra por aquellos años, también llamados nativistas, como parte de ese bullir de nacionalismos a raíz del estallido mexicano:

En el plano de la cultura, el clima de efervescencia nacionalista y social se reflejó en la aparición de varias novelas que expresaban los acuciantes problemas que aquejaban a la sociedad latinoamericana sometida por los monopolios imperialistas y dictaduras entreguistas. Así en La vorágine (1924), el colombiano José Eustasio Rivera incursionó con profundidad en el tema de la despiadada explotación

8 Eric Hobsbawm, La era del imperio (1875-1914) (Barcelona, España: Editorial Crítica, 2013).

9 Oswald Spengler, La decadencia de Occidente (Madrid, España: Editorial Espasa-Cape. S. A., 1966). 
soportada por los trabajadores de las grandes plantaciones de caucho situadas en medio de la selva. Por su parte, el venezolano Rómulo Gallegos recogía en Doña Bárbara (1929) toda la dura vida en una hacienda patriarcal de Los Llanos de Venezuela, mientras el argentino Ricardo Güiraldes en Don Segundo Sombra (1926) describía con crudeza las actividades del humilde gaucho. Casi en forma paralela, hacía su aparición en el Caribe la poesía negrista con las óperas primas del puertorriqueño Luis Palés Matos y el cubano Nicolás Guillén, a la vez que en el campo de la antropología se realizaban las rigurosas investigaciones dedicadas a los aportes de los esclavos africanos y sus descendientes a la formación nacional de Brasil y Cuba, realizadas por Gilberto Freyre y Fernando Ortiz, respectivamente. ${ }^{10}$

Pero ese auge de nacionalismos provenientes de sectores no tradicionales fue cercenado progresivamente por una estela de dictaduras y golpes de Estados, desde 1948 en Colombia, hasta 1973 en Chile. Estos ahondaron de manera paulatina en el desencanto por la búsqueda de modelos alternativos dentro del desarrollo del capitalismo latinoamericano, cuyos modelos tradicionales se habían creado desde las exportaciones de materias primas desde la segunda mitad del siglo XVIII.

Entre 1918 y 1973, se produjo este ciclo fallido de búsqueda de nacionalismos y reformismos por parte de fuerzas y sectores sociales no tradicionales. Precisamente, dentro de ese lapso y en concordancia con él, se desplegó desde la intelectualidad regional otras formas discursivas de ver y comprender el desarrollo histórico de Latinoamérica. Pero no solo desde los reflejos y tratamientos del arte y la literatura con moldes o influencias europeas, sino, además, desde la búsqueda de una interpretación de la cultura como un sistema de relaciones sociales estructurado a partir de sus cosmovisiones autóctonas y el devenir histórico.

De ese modo, desde los años veinte del pasado siglo, las vanguardias latinoamericanas, imbuidas en las relecturas de Occidente sobre la existencia humana, buscaron, a la par de una atemperación universal, un mayor compromiso social y político de sus artistas y escritores con sus sociedades a través de sus obras para sumergirse en otras formas de ver y entender sus respectivos países.

\section{Vanguardias comprometidas para una historia cultural del siglo $\mathrm{XX}$}

Así, una comprensión propia de un continente con casi cinco siglos de colonización dentro de la temporalidad de la cultura occidental, de poco menos de 3000 años de evolución modélica, fue más urgente que la actualización con dicha evolución. Para muchos intelectuales latinoamericanos era preciso explicar y mostrar el continente desde su propio decurso, paralelo al occidental y con similar antigüedad, aunque sin rechazar del todo la huella europea. Por el contrario, la interacción, forzada o no, de ambas civilizaciones, fue clave esencial

10 Sergio Guerra, Nueva historia mínima de América Latina. Biografía de un continente (Santo Domingo, República Dominicana: Archivos de La Nación, 2015). 
de varios escritores vanguardistas en sus obras. Dicha visión contuvo una mayor riqueza interpretativa ante la tradición de explicar a América Latina solo desde los conceptos, los métodos, las historia y el trascurso del tiempo europeo, fenómeno que hoy no pocos académicos e intelectuales latinoamericanos continúan reproduciendo. Los vanguardistas comprendieron que desde las aspilleras de un castillo medieval carolingio no podía divisarse correctamente las lógicas de las sociedades americanas.

En América Latina el vanguardismo tuvo similares o distintas asunciones políticas en torno a la preocupación social, en dependencia de las situaciones socioeconómicas de cada país. Varios de los pintores muralistas mexicanos David Alfaro, José C. Orozco y Diego Rivera - se identificaron con la dualidad, pero otros como el brasileño - véase las propuestas de la Semana del Arte Moderno de Sao Paulo 1922 - o el argentino - grupos pictóricos Florida, Boedo y La Boca-, fueron más cautos hacia las zonas políticas. De modo general, las vanguardias en nuestro continente a partir de los años veinte abrieron puertas a las miradas críticas sobre distintas realidades sociales, como el indigenismo, la vida obrera, el mundo rural y otros, logrando mucho más que una actualización internacional. A través de esos reflejos se observó un compromiso sociopolítico del creador no visto antes.

Los novelistas latinoamericanos, surgidos en el fragor de los movimientos vanguardistas, asumieron de manera notable tal responsabilidad social en sus obras. De modo previo, el costumbrismo, como recurso y estilo de la novela del decimonónico, permitió a varias generaciones de novelistas precedentes mostrar, describir y criticar sus sociedades. Pero lo hicieron sin desarrollar una mirada o interpretación desde las autoctonías históricas. Sus lenguajes y enfoques ideológicos, más otros recursos escriturales, si bien aportaron a las nacientes identidades, fueron esencialmente europeos. Reprodujeron de modo mayoritario la mirada del colonizador sobre nuestras realidades y sus sistemas de organización. ${ }^{11}$ De ese modo, la novela latinoamericana del XIX, se desarrolló como fuente ideológica y reproductora del universo social rectorado por las burguesías nacionales en formación.

Sin embargo, durante el auge vanguardista de la primera mitad del siglo XX, la novelística comenzó a desarrollar dos estéticas ilustrativas de nuestras sociedades que propusieron nuevas miradas y enfoques para otra comprensión del continente. No se trataba necesariamente, de discursos novelísticos para darle voz a los tradicionalmente dominados, negros, indígenas, mujeres, obreros y campesinos, fue mucho más. Ambas maneras desplegaron una totalidad discursiva de la historia de América Latina vista desde su propia cultura y no desde los moldes europeos, aunque sin desatenderse

11 Antonio Álvarez Pitaluga, «La historia en la novela cubana del siglo XIX», Revista Upsalón, n. ${ }^{\circ} 2$ (2004). 
del todo de los últimos. Escribir y explicar a América Latina con una lógica cultural propia, mediante un género de creación europea y occidental, como la novela, fue uno de los grandes méritos de tales estéticas. No obstante, todavía a finales de siglo XX y principios del XXI ambas continuaron siendo asumidas de modo convencional como estilos o formas de mostrar a Latinoamérica al lector regional y universal. ${ }^{12}$

El realismo mágico y lo real maravilloso, fueron en sus inicios dos estéticas literarias exponentes de la vida sociocultural del continente. Otros autores, también han visto en sus características las condiciones ilustradoras de una y otra. Hasta inicio del siglo XXI, tanto el realismo como lo real, siguen siendo vistos con más bondades ilustrativas que interpretativas para la historia global del continente, además, como categorías literarias más aptas más mostrar que para demostrar. Y, sin embargo, muy poco se han visualizado desde la ciencia histórica como fuentes instrumentales para la investigación sociocultural de la región, potencialidad muy poco aprovechada por los cultivadores de Clío.

Sin conocer sus bases históricas, ni las respectivas formaciones y aspiraciones intelectuales de Asturias y Carpentier, hay enfoques que las conciben como una misma estética o categoría, otros como continuidades discursivas; incluso, existen textos en los cuales se califica a Carpentier y su obra dentro del realismo, algo inverosímil. Pero nada más distante de la realidad. Ambas categorías proyectan y entienden a América Latina desde escenarios propios. Como continuaremos explicando, entendemos que son categorías y modelos diferenciados con determinados vínculos sociohistóricos comunes.

A pesar de dicha tendencia desde las historiografías literaria e histórica del continente, el realismo y lo real pueden ser asumidos como sendos modelos interpretativos de nuestras sociedades. Es cierto que hasta el presente ha predominado el criterio, con matices literarios, de examinar a estos como discursos ilustradores de la autoctonía latinoamericana. Quizás una de las razones de mayor peso para concebir tal juicio y utilidad, haya radicado en el hecho de que no pocos de los estudios sobre ambos han sido emprendidos regularmente desde la literatura y sus distintos especialistas, con una concepción fragmentada de la sociedad que impide visualizarla con un carácter relacional. Los pocos acercamientos desde la historia, también han adolecido de tal segmentación. De hecho, los historiadores, rara vez han emitido juicios en sus obras sobre cómo incorporar y aplicar sus fundamentos a la investigación histórica del continente, más aún a su historia cultural. La aplicación en la labor profesional de métodos como

12 Monique Nomo Ngamba, «El "Realismo mágico” y lo "Real maravilloso": dos visiones de la literatura postcolonial», Intercambio/Échange, n. ${ }^{\circ} 1$ (2016), en: https://repositori.udl.cat/bitstream/handle/10459.1/58545/intech_a2016n1p106.pdf?sequence=1\&isAllowed=y. 
el comparativo, el positivista, el marxista y otros, han sido «suficientes» para la labor del historiador nacional y americanista en las últimas décadas. ${ }^{13}$

No cabe duda de que las obras de Asturias y Carpentier, junto al realismo mágico y lo real maravilloso, han sido objetos de amplios estudios desde literatura, pero no tanto así desde la historia; de allí el interés y el énfasis de este artículo al analizar sus potencialidades para las interpretaciones de la historia cultural de América Latina. Las dos categorías contienen una valiosa riqueza de contenidos y recursos que las proyectan como modelos de comprensión de la universalidad social. Ahora bien, ¿por qué y cómo ambas categorías pueden ser consideradas modelos de interpretación? Expliquemos.

\section{Lógicas desde Latinoamérica, la historia como sustento de la literatura}

Al partir de la máxima de que la literatura es reflejo de la sociedad y su devenir histórico, Miguel Ángel Asturias (1899-1974) y Alejo Carpentier (1904-1980), fueron los dos principales intelectuales que propusieron al realismo mágico y a lo real maravilloso, respectivamente, como visiones orgánicas y explicativas de las autoctonías latinoamericanas a través de su literatura en la primera mitad XX. Sus intenciones se asentaron en una organicidad que los enlazaba con las evoluciones históricas de sus respectivos países y regiones. Asturias veía en el realismo y su componente onírico una forma esencial de interpretar la historia y la vida indígena y rural del continente, ya que:

El indio piensa en imágenes; él ve las cosas no tanto como fenómeno en sí, sino que las traduce en otras dimensiones en las cuales desaparece la realidad y aparecen los sueños, donde éstos metamorfosean en formas visibles y palpables. ${ }^{14}$

Asimismo, Carpentier asumía en lo real una ventana explicativa de la historia americana:

Lo real maravilloso se encuentra a cada paso en las vidas de hombres que inscribieron fechas en la historia del Continente y dejaron apellidos aún llevados: desde los buscadores de la Fuente de la Eterna Juventud, de la áurea ciudad de Manoa, hasta ciertos rebeldes de la primera hora o ciertos héroes modernos de nuestras guerras de independencia $[\ldots] .{ }^{15}$

13 Para un balance de la historiografía contemporánea sobre América Latina puede consultarse: Carlos A. Aguirre, Itinerarios de la historiografia del siglo XX: de los diferentes marxismos a los varios annales (Cuba, La Habana: Centro de Investigación y Desarrollo de la Cultura Cubana, 1999); Sergio Guerra, Cinco siglos de historiografia latinoamericana (La Habana: Editorial de Ciencias Sociales, 2009), (segunda edición). Eduardo Torres-Cuevas, La Historia y el oficio del historiador (La Habana, Cuba: Editorial Imagen Contemporánea, 2011); E. Bohoslavsky, «Algunas reflexiones sobre la historiografía actual de América Latina», Cuadernos del GESCAL, año 1, n. ${ }^{\circ} 1$ (2013).

14 Robert G. Mead, citado por Branka, 1991, 30.

15 Alejo Carpentier, El reino de este mundo (Ciudad de México, México: Editorial, 1949). 
Sus compromisos intelectuales les permitieron visualizar las realidades sociales con puntos de partida en Centroamérica, para Asturias, y el Caribe, para Carpentier. Sus militancias sociales contra las dictaduras de Manuel Estrada Cabrera, en Guatemala, y Gerardo Machado, en Cuba, les dotó, además, de sólidos criterios políticos sobre las distintas subordinaciones de grupos y sectores sociales que, contrariamente a los estigmas de discriminación a los cuales estaban sometidos, constituían núcleos fundamentales de las aportaciones formativas de la historia latinoamericana. De ese modo, sus visiones sociales se articularon mediante interpretaciones originarias que contribuyeron a otra formación identitaria, la de una literatura continental, a partir de las cosmovisiones de sus habitantes originarios y transculturados.

Durante la primera mitad del siglo XX, momento histórico en el que nacieron sus respectivas miradas sociales, comenzó de modo paralelo una nueva etapa de la rica acumulación de mezclas culturales del continente, iniciada desde el siglo XVI. Hasta principios del XX, las clases sociales dominantes del continente y sus élites intelectuales habían admitido las mezclas y los sincretismos indígenas, españoles y africanos, principalmente, como las bases históricas de sus respectivas realidades sociales, pero no como posibles modelos de interpretación social de estos; de hacerlo, hubiesen estado compelidas a aceptar los roles protagónicos de estos grupos y culturas dominadas en las formaciones nacionales y general de la cultura latinoamericana. Por tanto, aceptaban sus presencias otorgándoles posiciones de subordinación socioeconómica y cultural dentro de los sistemas de organización social. Esa otra relectura no tradicional de la historia, que cobró vida en las obras de Asturias y Carpentier, iba contra tales lógicas tradicionales de dominación.

Se trataba de dos concepciones distintas de la historia de América. Desde las élites tradicionales se veía a este continente como el conjunto de Estados hegemonizados en clases y grupos sociales divididos en dominadores y dominados con homónimas culturas, es decir, oficial y popular, al estilo de liberalismo tradicional y el positivismo. Asturias y Carpentier oteaban la historia desde otra dimensión, una integralidad de razas e identidades que da paso a una historia cultural a partir de una totalidad americana.

En 1940, el antropólogo Fernando Ortiz (1881-1969), publicó su conocida obra Contrapunteo cubano del tabaco y el azúcar. ${ }^{16}$ En ella, se expone, con asombrosa minuciosidad histórica y profundo aliento antropológico, el concepto de transculturación, que sustentaba la lógica histórica de Latinoamérica enarbolada por los dos novelistas: «Entendemos que el vocablo transculturación expresa mejor las diferentes fases del proceso transitivo de una cultura a otra,

16 Fernando Ortiz, Contrapunteo cubano del tabaco y el azúcar (La Habana, Cuba: Editorial de Ciencias Sociales, 1983). 
porque éste no consiste solamente en adquirir una distinta cultura, que es lo que en rigor indica la voz anglo-americana aculturación $[\ldots] \gg .^{17}$

A través del concepto es posible analizar el lento, pero continuo proceso de mezclas entre las diferentes culturas que confluyeron en América Latina desde el siglo XVI, para conformar y dar vida a un nuevo ser civilizatorio de la modernidad, el hombre latinoamericano. Se trata de un proceso de larga duración que interpreta un fenómeno inédito en el nivel global, iniciado con los albores del capitalismo mundial. En Latinoamérica, se encontraron por primera vez tres grandes grupos culturales, europeos, africanos e indígenas, que casi siempre de modo forzado fueron fusionándose durante casi quinientos años de larga duración braudeliana. América era para estos grupos el inicio de una nueva vida, deseada o no, y para sus sucesivos descendientes, el lugar de la existencia completa de sus vidas.

Los procesos de sincretismos culturales pulularon por casi toda América Latina durante los periodos coloniales, independentistas y republicanos, estructurando y desestructurando sociedades, nacionalidades, producciones artísticas y literarias, mentalidades y sistemas de relaciones sociales y de poder. Cierto es que los niveles y los porcentajes de mezclas culturales en cada región o país no fueron iguales o similares, en algunos casos llegaron a ser distintos. Según las cantidades de poblaciones indígenas, europeas y africanas, de los procesos históricos propios - y dentro de ellos - los asociados al tratamiento y la abolición de la esclavitud durante el XIX, las formaciones nacionales tuvieron procesos de transculturación mediante diferentes expresiones e intensidades. También, las mentalidades de las clases dominantes en torno a sus ideales socioeconómicos y paradigmas culturales jugaron un papel destacado en dichas construcciones nacionales. La siguiente tabla nos da una idea aproximada de la entrada de esclavos al continente, lo que permite proyectar los distintos niveles e influencias de las culturas africanas en las transculturaciones americanas.

Cuadro 1. Cantidad de esclavos africanos llegados entre los siglos XV-XIX y sus zonas de entrada en América

\begin{tabular}{|c|c|c|c|c|c|c|c|}
\hline Años & $\begin{array}{c}\text { América } \\
\text { del Norte }\end{array}$ & $\begin{array}{c}\text { Caribe } \\
\text { británico }\end{array}$ & $\begin{array}{c}\text { Caribe } \\
\text { francés }\end{array}$ & $\begin{array}{c}\text { Posesiones } \\
\text { holandesas }\end{array}$ & $\begin{array}{c}\text { Indias } \\
\text { occidentales } \\
\text { danesas }\end{array}$ & $\begin{array}{c}\text { América } \\
\text { española }\end{array}$ & Brasil \\
\hline $1501-1866$ & 388747 & 2318252 & 1120,216 & 444728 & 108,998 & 1292,912 & 4864,374 \\
\hline
\end{tabular}

Fuente: elaboración propia a partir de los datos ofrecidos en la obra de K. Morgan, Cuatro siglos de esclavitud trasatlántica (Barcelona, España: Editorial Crítica, 2017), 47.

Como se observa, el Caribe, Centroamérica y territorios andinos donde se ubican naciones como Ecuador, Colombia, Perú, Venezuela; y otros como

17 Ibíd., 96. 
México, junto a Brasil, asimilaron la mayor cantidad de esclavos africanos. Unido al conjunto de sus poblaciones indígenas, dicha entrada incidió en las actuales composiciones demográficas, étnicas y culturales de estas regiones, proceso muy presente en ambas categorías literarias.

El concepto de transculturación y las categorías realismo mágico y real maravilloso, brotaron con relativa coincidencia cronológica en el pensamiento latinoamericano de la primera mitad del siglo XX. El concepto, de bases antropológicas e históricas, ejerció ciertas influencias sobre la estética de lo real maravilloso, como lo ha demostrado recientemente, la investigadora italiana Fulvia de Feo. ${ }^{18} \mathrm{Su}$ indagación prueba los profundos vínculos entre la historia continental y la visión escritural e interpretativas a lo largo de la prosa carpenteriana. Queda aún pendiente el estudio comparativo entre el concepto de transculturación y el realismo mágico, sobre todo desde la obra de Asturias. Sujeta a probables hipótesis, una triangulación investigativa entre transculturación, realismo mágico y real maravilloso, podría brindar nuevas luces para la historia cultural de América Latina.

Desde su nacimiento dicho triángulo interpretativo, se presentó como una alternativa de pensamiento con visos contrahegemónicos para la intelectualidad del continente.

No obstante, como ya se ha dicho, de modo tradicional el realismo mágico y lo real maravilloso han sido vistos como categorías más literarias y descriptivas, que como posibles modelos de interpretación histórica.

Es dable que esa encuadernación intelectual responda a varias realidades sociales, destacándose entre ellas las siguientes: en primer lugar, por las realidades comerciales que marcaron el devenir de ambas, sobre todo para el realismo mágico con el inicio del llamado boom de la literatura latinoamericana desde 1960. El interés editorial europeo, encabezado por la editorial española Seix Barral, si bien les abrió las puertas de Europa y sus lectores a varios escritores que articularon sus obras desde el realismo mágico, también dotó al fenómeno del boom de un sentido comercial a partir de sus niveles de ventas. Desde sus dividendos el componente ilustrativo fue una ventana provechosa con cierto exotismo ante las racionalidades europeas, que no dejaba de vernos con un histórico folclorismo colonial, renovado por esta explosión editorial.

En segundo lugar, lo real maravilloso fue estructurado sólidamente por Carpentier a través de tres de sus obras esenciales, El reino de este mundo (1949), Los pasos perdidos (1953) y El siglo de las luces (1962). Sin embargo, el decurso de la revolución en Cuba desde 1959, país del cual Carpentier no quiso hacer dejación, pudo haber restado con distintos enfoques políticos o de rechazo, hacia ese telúrico fenómeno histórico, una mayor divulgación de sus

18 Fulvia María de Feo, «La huella de Fernando Ortiz en la cosmovisión histórica de Alejo Carpentier», Revista de la Biblioteca Nacional José Martí, n. 2 (2016): 56-65, http://revistas.bnjm.cu/index.php/ revista-bncjm/article/view/3816. 
utilidades investigativas para la historia continental hasta casi finalizado el siglo XX, menos aún asumir sus primas contrahegemónicas.

Finalmente, la continuación a lo largo del siglo XX del pensamiento positivista en la historiografía histórica, que, por su propia naturaleza fática y metodológica, se resistió a aceptar la literatura y en especial su novelística, como una fuente más para el trabajo del historiador.

La historia positivista, no superada del todo aún, marca distancia con la literatura y el arte al endilgarles una fuerte carga de ficcionalidad a partir de la voluntad, la imaginación y la libertad estética del autor, mientras ella se proclama como una ciencia cuasiinfalible porque se ajusta a los hechos probados y documentados. Con esa visión, procedente del liberalismo tradicional, le resta al concepto de cultura su capacidad de producción y reproducción social. De allí que el realismo y lo real no tengan aparente utilidad para la historia y el historiador positivista, cuando el análisis relacional demuestra lo contrario; sin descontar que prueba, además, de manera irrefutable, que la ficcionalidad de la historia es tan real como la del arte y la literatura a partir de sus relaciones con el poder y las ideologías. La historia como conocimiento y ciencia está interrelacionada con distintas subjetividades, intereses, contextos y épocas. Subjetividad y ficción constituyen una misma capacidad intelectual del hombre al plasmar desde la historia, el arte o la literatura, sus diferentes apreciaciones sobre la realidad. Quizás ambas pueden ser sintetizadas en una palabra, imaginación.

El historiador positivista encuadra al realismo y lo real como estéticas de la literatura, entendida como aérea de conocimiento específica dentro de una historia de la cultura, que a su vez fragmenta la visión relacional desde la cual se construye la historia cultural.

\section{La historia real del realismo}

Antecedida por El señor Presidente (1946), la novela Hombres de maiz ${ }^{19}$ catapultó a la figura de Miguel Ángel Asturias dentro de las letras latinoamericanas casi al concluir la primera mitad del siglo XX. En la segunda obra expuso el entramado intelectual desde el cual planteó la aplicación del realismo mágico para la comprensión general de la historia y las sociedades de Centroamérica, y con especial atención de su Guatemala natal. El realismo mágico tuvo sus orígenes en la Europa occidental de 1925, sacudida por la postguerra de la I Guerra Mundial y el repensar existencial que generó el fin de aquella contienda y sus traumáticos resultados.

Ese año, el crítico de arte Franz Roh, acuñó el término que posteriormente, alcanzaría dimensiones internacionales. La traslación al campo de lo real, de lo común y lo cotidiano, de la fantasía, los componentes mágico-religioso de las tradiciones y la religión como práctica espiritual, junto a la sugestión onírica del

19 Miguel Ángel Asturias, Hombres de maíz (Buenos Aires, Argentina: Editorial Losada, 1949). 
hombre occidental, fueron elementos esenciales de la estructura realista. En la novela modernista de la época, autores de la talla de James Joyce y Frank Kafka, también influyeron sobremanera en las recreaciones fantásticas que aparecieron en posteriores obras realistas americanas.

Como forma de entender la realidad, el realismo mágico asume desde Occidente la posibilidad de ver el mundo y sus cotidianeidades como un universo social ensamblado a partir de dos dimensiones, una racional y otra onírica. Ambas se estructuraron a través del decurso lineal de la historia europea. La sucesión cronológica y ordenada de épocas y etapas históricas en Occidente, desde la antigüedad griega hasta la contemporaneidad industrial de inicios del siglo XX, concibió el desarrollo de una racionalidad social. Esta tuvo en la acumulación de saberes - arte, literatura, filosofía, historia, ciencias, política, economía, guerra y otros-, más las distintas prácticas de la existencia humana en esa parte del planeta durante siglos, un sólido fundamento teórico-práctico que explica la existencia del hombre, sus sentidos, objetivos y destinos.

Tal raciocinio existencial también se articuló desde un universo alucinante en el cual varios componentes fantásticos e irreales formaron parte de la razón interpretativa de la vida biológica y social del hombre. Los rituales mágicos del hombre antiguo ante los fenómenos naturales sin explicación inauguraron esa manera de comprender la existencia, y que después fueron acompañados por concepciones religiosas, leyendas, mitos y tradiciones del imaginario medieval, hasta las visiones utópicas de la era capitalista con ciertos tintes sociopolíticos al estilo de Utopía. ${ }^{20}$

El mundo real y el imaginado armaron el binomio interpretativo del realismo mágico, que se conecta a su vez con la vanguardia europea a través de los fundamentos del surrealismo; por lo que, la esencia del realismo fue y es, una, narración naturalizada de lo fantástico. ${ }^{21}$

Dicha interpretación sociocultural se presentó como anillo al dedo para varios escritores latinoamericanos de la primera mitad del $\mathrm{XX}$, ansiosos por mostrar sus realidades con claves realistas. Desde sus pensamientos, las visiones mágico-religiosas de las culturas ancestrales indígenas se acoplaban con el sentido onírico occidental. Estas eran, desde hacía siglos, los resortes básicos de una cosmovisión del mundo de sus civilizaciones y grupos culturales en buena parte del continente. Varios novelistas encontraron en la visión histórica y la estética social del realismo mágico un lenguaje expositivo sobre el continente.

$\mathrm{Su}$ asunción y utilidad vertieron frutos en pocos años. La circulación local de la novela comenzó a aumentar entre nuestros países hasta regionalizarse e iniciar posteriormente, una internacionalización con la llegada de los años sesenta.

20 Tomás Moro, Utopía (Madrid, España: Círculo de Bellas Artes, 2011).

21 Daniel Centeno, «Las formas de lo inverosímil», citado por Esther Magar, en: https://relatosmagar.com/ diferencia-entre-realismo-magico-y-real-maravilloso/. 
El boom de la literatura latinoamericana, desde 1960, permitió que destacados jóvenes novelistas de entonces, publicaran varias obras desde los entramados del realismo mágico. El triunfo de la Revolución cubana, el legado de la novelística continental desde el XIX, la evolución histórica y el papel de la historia en los Estados nacionales, más otras influencias, como la obra de Alejo Carpentier, entonces en pleno ascenso, conformaron la plataforma desde la cual el boom comenzó el lanzamiento de la novela sudamericana en Europa. En el Viejo Mundo se había despertado una fuerte curiosidad por la América Latina del siglo $\mathrm{XX}$. El primero aceptó de muy buena gana una novelística que con lenguaje propio estaba dispuesta a narrar su historia y otras maneras de entender realidades allende del Atlántico.

Pero una diferencia dibujaba la visión europea y la de los propios sudamericanos sobre sus tierras. Mientras el realismo mágico europeo no dejó de ver la historia desde dos universos separados, civilización y barbarie, y, por tanto, América Latina se mantuvo como escenario de barbarie que necesitaba ser colonizado-educado cíclicamente - civilizada - , nuestro realismo mágico establecía otra lógica dual de la existencia americana: el americanismo transcultural como forma de entender el universalismo humano.

Monique Nomo habla de una dualidad cultural para explicar el boom literario entre los sesenta y setenta, la cultura de la tecnología y la de la superstición; ${ }^{22} \sin$ embargo, con una visión más global, tal dicotomía se expresa mejor en el nivel de Europa y América Latina. En las dos, el realismo mágico tuvo interpretaciones respectivas sin soslayar sus iguales bases de concepción. A pesar de las irracionalidades de la primera y la segunda guerras mundiales, Europa insistió en concebirse como una cultura racional y tecnológica, donde las supersticiones antiguas y medievales quedaron en los imaginarios históricos del pasado y en los componentes oníricos del realismo. Y ante sus lógicas intelectuales, América Latina se perfiló como una cultura de desventajas y supersticiones históricas; de allí que el realismo mágico no llegó a ser una categoría literaria que cambiase la visión tradicional sobre el continente desde la racionalidad occidental.

El interés occidental por saber de América Latina desde la novelística del realismo mágico fue latente hasta casi finales del siglo XX. Cuando a lo largo de los años setenta se produjo el tránsito del boom al postboom literario del continente, ${ }^{23}$ el realismo mágico de corte indigenista, agrario e historicista asumió entonces un estilo más occidentalizado y urbano, logrando mantener ese interés internacional. El postboom etiquetó una identidad cosmopolita en función de los

22 Nomo Ngamba, 108.

23 Nelson González-Ortega, «La novela latinoamericana de fines del siglo XX: 1967-1999. Hacia una tipología de sus discursos» (sin fecha), en: https://www.hf.uio.no/ilos/tjenester/kunnskap/sprak/nettsprak/ spansk/lesesal/innforingspansklitteratur/tekster/nelsonmoderna.pdf. 
intereses del mercado, contribuyendo desde lo urbano a la imagen forclorizada que el boom había iniciado. ${ }^{24}$

La chilena Isabel Allende con La casa de los espiritus, ${ }^{25}$ y la mexicana Laura Esquivel, con, Como agua para chocolate,${ }^{26}$ dieron a conocer ambas obras bajo los códigos de este segundo realismo mágico, más editorial que antropológico. La demanda internacional facilitó relativas rápidas traducciones de estas y otras novelas al inglés, francés, alemán e italiano, las lenguas dominantes de Europa occidental y Estados Unidos.

En la dualidad occidental, civilización-barbarie, es decir, Europa-América Latina, el realismo latinoamericano del boom y el postboom fue una versión transoceánica del realismo europeo, su par filosófico y existencial. Se acogió en Europa para conocer lo exótico, lo presencial colonizado, aunque no comprendido en su totalidad. Una vez escrutado, el interés editorial decayó y el realismo perdió preferencias.

Pero la comprensión histórica siguió sin quebrar las tradiciones intelectuales y las lógicas civilizatorias de la racionalidad occidental. El problema es que con el realismo mágico sucede lo mismo que con las ideologías de la modernidad, ya que no existe, el realismo en singular, sino los realismos en plural.

En ese sentido, el liberalismo europeo del siglo XVIII, por ejemplo, abogaba por la libertad y la individualidad como máximas ideológicas del capitalismo en expansión, pero en América, los pensadores liberales, por el contrario, justificaban la esclavitud de la época en sus tierras. ${ }^{27}$ En Europa el realismo de Roh admitía los componentes irreales como una fantasía natural que era imaginada, inventada, soñada, hasta ser incorporada a la realidad como parte del inconsciente freudiano con ojos surrealistas; mientras en América Latina, lo irreal y fantástico es consustancial a la realidad histórica, forma parte intrínseca de la historia y la sociedad latinoamericanas. Esta es una idea enunciada por Alejo Carpentier en su prólogo a El reino de este mundo ${ }^{28} \mathrm{el}$ cual abordaremos más adelante. Tal vez por eso, paralelamente, la novelística construyó otra estética americana con un grado de autonomía distinto: lo real maravilloso.

Pero el realismo mágico no solo tuvo en Europa occidental y en América Latina sus conocidas expresiones, también ancló en la literatura de América del norte, ya que, al fin al cabo, Occidente emprendió la extensión de sus límites en las tierras del Potomac con el inicio de la colonización americana. La invención de Yoknapatawpha en la obra de William Faulkner influenció sobremanera en

24 Jorge Volpi, «El fin de la narrativa latinoamericana», Revista de Crítica Literaria Latinoamericana, n. ${ }^{\circ} 59$ (enero-junio, 2004): 33-42, https://as.tufts.edu/romancestudies/rcll/numero59.htm\#numeros.

25 Isabel Allende, La casa de los espíritus (Santiago de Chile, Chile: Editorial Sudamericana, 1982).

26 Laura Esquivel, Como agua para chocolate (Ciudad de México, México: Editorial Planeta, 1989).

27 Jorge Luis Acanda, Sociedad civil y hegemonía (La Habana, Cuba: Centro de Investigación y Desarrollo de la Cultura Cubana, 2002).

28 Carpentier, El reino de este mundo. 
el Macondo de Gabriel G. Márquez de la segunda mitad del XX. ${ }^{29}$ No obstante, Asturias fue visualizado como el pionero literario del realismo en nuestras tierras, aunque tal vez, ajustándonos a la historia sea mejor decir, del realismo rural e indigenista.

La reencarnación y la presencia intermitente de Gaspar Ilóm a lo largo de Hombres de maíz, en diferentes contextos, situaciones y decursos del tiempo, simbolizan el universo alucinador de la cultura indígena americana, donde la imagen es una construcción básica de su cosmovisión. En ella, el componente fantástico de la realidad tiene terrenalidad y sentido. En una entrevista posterior, Asturias dio una idea global de esa comprensión realista:

\begin{abstract}
El hecho tan corriente entre nosotros es que la imaginación popular transforma los sucesos reales en leyenda y las leyendas llegan a encarnar acontecimientos de la vida diaria. A mí me parece muy importante en el existir americano esa zona en que se confunden, sin límite alguno, la irrealidad real de lo legendario con la vida de los personajes. ${ }^{30}$
\end{abstract}

Y es que en América Latina la imagen es un recurso vital en la formación de la memoria histórica y la visión del mundo. Desde los códices prehispánicos se puede rastrear ese universo iconográfico y simbólico que tanto ha influido en la novelística. La imagen como es una forma de representación y construcción de la historia americana, también ha permitido imaginar y entender la historia universal desde América Latina. Paradiso, novela indispensable de José Lezama Lima para entender la imagen como fuente de la historia americana y universal, ${ }^{31}$ es un ejemplo recurrente de tal posibilidad, aunque de difícil asimilación y atípicos caminos conceptuales para una visión tradicional que entiende la historia solo a través de... documentos de archivo.

A su vez, en el realismo mágico de Asturias el sentido del tiempo nace del universo mítico del indígena — por definición histórica, el colonizado-, que trascurre de modo circular mediante ciclos constantes, ya que lo pasado no caduca, no se convierte en recuerdo, en memoria evocada, sino que participa y es parte de un presente. Es un pasado actual cuyos protagonistas son participantes del presente, muchas veces reencarnados en otros seres vivientes mediante su «nahual». Pero la temporalidad de Occidente — por realidad histórica, el colonizador-, se organizó desde un sentido lineal, de sucesión continua y sin reversibilidades.

Ambas dimensiones cronológicas y racionales se enfrentan en la obra de Asturias en la pugna por el maíz como fuente de cultura o de riqueza comercial.

29 Gabriel García, Cien años de soledad (Madrid, España: Editorial Planeta, 1967).

30 F. Donahue, «Miguel Ángel Asturias: su trayectoria literaria», Cuadernos Hispanoamericanos, n. ${ }^{\circ} 68$ (1965): 78.

31 José Lezama, Paradiso (La Habana, Cuba: Ediciones Unión, 1966). 
De allí que el realismo mágico latinoamericano ilustra y valoriza una parte sustancial de nuestra historicidad frente a lo foráneo; pero, al tener su invención una raíz europea, no logra articular del todo las fusiones culturales - indígenas, africanas, europeas - como una única entidad cultural. Mantiene, al igual que el europeo, sus grupos culturales como entidades paralelas en una misma tierra. Si bien Asturias reconoció el mestizaje y la naturaleza como factores claves en su obra, el primero lo vio con más hincapié en lo indígena y el segundo como riqueza y herencia de los escritores nativistas que lo habían antecedido; por tanto, no llegó a consolidar a su máxima plenitud una concepción de la universalidad histórica americana:

Me siento orgulloso porque correspondo a esa raza de hombres en las que se han mezclado las dos aguas, los dos océanos, los dos sentires, el indígena y el europeo. El europeo que llegaba cansado y agobiado a nuestras tierras y el indígena [....$^{32}$

Y es que cuando se pretende ver nuestro mundo con los ojos del otro de Todorov, se divisa con las miradas de nuestros propios colonizadores. La profecía intelectual del pensador europeo confirma así en la racionalidad formal de Max Weber, ${ }^{33}$ y el sentido común de Antonio Gramsci. ${ }^{34}$ La razón occidental predomina entonces sobre la organicidad cultural latinoamericana.

Pensar el realismo mágico latinoamericano desde las ciencias sociales reporta, también ventajas más ricas que las reflexiones anteriores. Puede llegar a ser un instrumento de investigación para el estudio social de la cultura, de los estudios culturales y, sobre todo, para su historia cultural, según las posibilidades y las realidades históricas de la región o el país.

Si entendemos la historia cultural como el estudio de la relación interdependiente entre el tiempo histórico y el hecho social, ${ }^{35}$ veremos que esta es en América Latina la interrelación entre su tiempo multicronológico de intertextualidades temporales con una progresiva y permanente transculturación de su acaecer histórico. Entendiéndola con un carácter relacional, su universalidad interpretativa desestima una conceptualización fragmentada de la economía, la política, la filosofía y otras áreas del saber y la sociedad. El encuadre tradicional entre arte y literatura reproduce una mirada renacentista-iluminista no superada del todo. La cultura de América Latina es, pues, la historia de su transculturada universalidad social.

32 Rita Guibert, «Miguel Ángel Asturias. Entrevista con Rita Guibert», 7 Voces (México: Organización Editorial Novaro, S. A., 1974), en: https:/www.literatura.us/miguel/rita.html.

33 Max Weber, Economía y sociedad (Ciudad de México, México: Fondo de Cultura Económica, 1997).

34 Antonio Álvarez Pitaluga, Revolución, hegemonía y poder. Cuba (1895-1898) (La Habana, Cuba: Fundación Fernando Ortiz, 2012).

35 Antonio Álvarez Pitaluga, La isla gigante. Cuba y su cultura contemporánea. Principales vínculos con América Latina (1959-2016) (San José, Costa Rica: Editorial Arlequín, 2018), 22. 
Lamentablemente, todavía suele verse en nuestras academias a la historia cultural y a la cultura latinoamericana ese estilo iluminista, al estilo del liberalismo dieciochesco y el positivismo desde fines del siglo XIX. Es decir, el arte y la literatura como entidades y producciones independientes del sistema organizacional del poder, de la economía y la política, cuando se sabe bien que ambas forman parte integral de cualquier sistema de organización social moderno y que muchas veces contienen entramados ideológicos, aunque no necesariamente las ideologías producen y reproducen a las dos. Cuando la antropología y la sociología culturales estudian en sentido microhistórico un proceso o una manifestación artística o literaria y no lo interrelaciona con el resto del engranaje social y los sistemas de relaciones de poder, quedan atrapadas también, en la visión positivista de las fragmentadas ciencias sociales.

Solo con una perspectiva relacional de la sociedad es posible que el historiador y otros científicos sociales puedan divisar las utilidades del realismo mágico como modelo de interpretación. A través de él, se puede conocer y entender sucesos culturales, tales como: el sentido del tiempo latinoamericano en la cosmovisión indígena y campesina, el universo histórico-visual indígena, la vida cotidiana e imaginarios populares - rurales y urbanos - , la fantasía como elemento cotidiano del pensamiento y las mentalidades, el dilema espiritual y material entre colonizador y colonizado y sus resultantes en la cultura continental, al estilo de Calibán; ${ }^{36}$ además, el carácter antropomórfico de las prácticas culturales indígenas y sus sólidos vínculos con la naturaleza. Si bien es cierto que tales elementos son conocidos, verlos como una integralidad y con su plena autoctonía, ayudarán a entender al realismo mágico como una ventana propia para asomarnos a nuestra historia.

Cuando el realismo rural e indigenista elaboró un discurso nacional y continental desde la espectacular trascendencia de la naturaleza, la historia y el hombre latinoamericano, dejó abierta una puerta investigativa para los científicos sociales, que aún no se aprovecha del todo. Asimismo, el segundo realismo, del postboom, mucho más urbano, se preocupó por los dramas individuales y existenciales de las sociedades de finales del siglo XX. Ambos enfoques constituyen un contrapunteo entre el relato nacional-continental y el individual-personal que permite obtener una visión global del continente, haciendo una similitud entre las historiografías regionales-nacionales y las microhistorias, tan frecuentes, pero a la vez tan inconexas entre ellas mismas y con la historia continental.

El investigador social puede encontrar en ese paralelismo dual una importante ventaja y utilidad para entender y explicar las historias globales de la región, para alcanzar así una visión general y de universalidad relacional de su pasado y presente. Poder llegar a una universalidad relacional lo convierte en un pensador social, algo pretendido, pero no logrado por muchos, más allá de extensos currículos y carreras académicas.

36 Roberto Fernández Retamar, Todo Calibán (La Habana, Cuba: Casa editorial ALBA, 2012). 
El realismo mágico sudamericano es una lógica de vida propia, otra racionalidad que, por no ser colonizadora, no es menos que otras, solo es distinta y tiene la capacidad de explicar una parte fundamental del sistema relacional de la cultura, a través de una modernidad de ya más de cinco siglos. El propio Asturias resumió sus deseos de entender a Latinoamérica desde el realismo:

\begin{abstract}
Yo creo que mi esfuerzo ha sido precisamente el encontrar la expresión americana con carácter universal; es decir, salir del aldeanismo, del criollismo, de las formas mínimas de nuestra manera de contar, y buscar como yo digo una forma americana, una expresión indo-americana que pudiera ser entendida por casi todos los hombres. ${ }^{37}$
\end{abstract}

\title{
Lo maravilloso de la historia latinoamericana
}

Pero ¿qué es la historia de América toda, sino una crónica de lo real-maravilloso? ${ }^{38}$ Cuando Alejo Carpentier (1904-1980), finalizó con esta pregunta su prólogo a El reino de este mundo, quizás no imaginó que había formulado a los lectores una de las interrogantes más telúricas y vigentes de la historia cultural de América Latina. Ver la totalidad de la historia de América a partir del modelo interpretativo de lo real maravilloso es todavía hoy una necesidad y posibilidad analítica de dimensiones universales. En perspectiva actual, lo real maravilloso tiene capacidades cognitivas y comprensivas de carácter histórico que le otorgan un mayor alcance de análisis frente a otros modelos interpretativos de la literatura continental.

Menos divulgado y comercializado que el realismo mágico, lo real maravilloso articula sus factores de análisis en componentes sociohistóricos no del todo coincidente con el primero. Porque mientras que el realismo es la articulación de una invención que sustenta una realidad social, lo real es el conjunto de una realidad histórica que conduce una visión atípica y contrahegemónica en la tradición occidental. Es cierto que es más conocido el realismo, pero no siempre lo más divulgado es lo más ajustable, depende de contextos e intereses. Esta idea necesita ser más explicada.

Como sabemos, este prólogo es el manifiesto intelectual de la estética de lo real maravillo, expuesta allí, pero diseminada a lo largo de la obra carpenteriana. No obstante, en el conjunto de su novelística existen tres obras que pueden condensar la armazón estructural de lo real maravilloso, en El reino de este mundo ${ }^{39}$ Los pasos perdidos $^{40}$ y El siglo de las luces. En estas, y en el resto de su producción, es posible detectar la escrupulosidad y la obsesión de Carpentier por el apego al hecho y la información histórica para construir las tramas y los

37 Manuel Martínez Azaña y Claude Mie, «Entrevista con Miguel Ángel Asturias, Premio Nobel». Revista Bulletin Hispanique (Francia), vol. 70, n. ${ }^{\circ}$ 1-2 (1968): 138.

38 Carpentier, El reino de este mundo, 17.

39 Ibíd.

40 Alejo Carpentier, Los pasos perdidos (La Habana, Cuba: Editorial Letras Cubanas, 2005). 
personajes de cada una de sus creaciones, requisito que también puede ser de mucha utilidad para el historiador de América Latina. En el prólogo dejó por sentada esa vinculación:

\begin{abstract}
Porque es menester advertir que el relato que va a leerse ha sido establecido sobre una documentación extremadamente rigurosa que no solamente respeta la verdad histórica de los acontecimientos, los nombres de personajes -incluso secundarios-, de lugares y hasta de calles, sino que oculta, bajo su aparente intemporalidad, un minucioso cotejo de fechas y de cronologías. ${ }^{41}$
\end{abstract}

La historicidad es un principio cardinal de lo real maravilloso. Carpentier sabía que los fundamentos, la narración y la comprensión de la historia no solo dotaban a su obra de una solidez narrativa muy particular, sino, además, de una fiabilidad sociocultural que todavía hoy los historiadores neopositivistas no logran entender ni aceptar. Empeñados en ver la novela como un complemento de la investigación histórica debido a su carga de ficcionalidad, soslayan así las marcadas posibilidades investigativas e interpretativas de lo real maravilloso. Sin comprender que la subjetividad autoral del novelista es la misma que la del historiador al producir, consciente o inconscientemente, dentro de un entramado relacional de intereses y poderes sociopolíticos del cual son piezas orgánicas. De ese modo, sus capacidades interpretativas de la historia y las sociedades latinoamericanas quedan truncadas con sus miradas decimonónicas en pleno siglo XXI.

Pero ¿cuál fue uno de los mayores fundamentos analíticos de la conocida escuela historiográficas de Annales en Francia, sino el estudio y la legitimación de las subjetividades humanas desde el pasado, que llamaron estudios de mentalidades e imaginarios populares?; o sea, son las mismas subjetividades que inspiraron al surrealismo como movimiento artístico y literario y de cierto modo, también al realismo mágico. Y nadie duda del peso y las aportaciones de la escuela de Annales durante casi setenta años, con varias generaciones de historiadores, que le dieron a la historiografía francesa el más largo reinado historiográfico internacional del siglo XX.

El peso de la hermenéutica de lo real maravilloso contiene una mayor profundidad fáctica que otras estéticas literarias continentales. Su estructura de análisis se asienta en cuatro elementos interrelacionados, ${ }^{42}$ que articulan a su vez el conjunto de las espirales evolutivas de la historia de América Latina con el inicio de la modernidad, estas son:

- Las emigraciones africanas entre los siglos XVI y XIX con todo el universo de aportaciones culturales y demográficas a las tierras de americanas. El arribo de millones de africanos en condiciones de esclavitud durante

41 Alejo Carpentier, La música en Cuba (Ciudad de México, México: Fondo de Cultura Económica, 1946), 16. 42 De Feo. 
cuatro siglos a tierras americanas incidió en las formaciones nacionales latinoamericanas con mayor o menor intensidad, dependiendo de las cantidades arribadas, destinos recibidos, funciones sociales y contextos históricos de cada región o país en formación. Sus universos culturales llegan hasta el presente mediante variados aspectos de nuestras culturas materiales e inmateriales.

- A su vez, el profundo mestizaje cultural que de manera única se dio en nuestras tierras a través de una transculturación permanente hasta nuestros días con base en las acumulaciones culturales de larga duración de las civilizaciones africanas, aborígenes y europeas, fenómeno muy particular del continente, ya que si bien durante siglos anteriores Occidente tuvo contactos e intercambios con civilizaciones del Oriente, estos no devinieron en profundas y sistemáticas transculturaciones, al menos hasta finales el siglo $\mathrm{XV}$, ni tampoco generaron nuevas civilizaciones. Tanto es así, que los orígenes y las estructuras culturales de larga duración de Occidente siguen siendo grecoromana ${ }^{43}$ Tal atipicidad fue vista desde Los pasos perdidos: porque aquí no se habían volcado, en realidad, pueblos consanguíneos, como los que la historia malaxara en ciertas encrucijadas del mar de Ulises, sino las grandes razas del mundo, las más apartadas, las más distintas, las que durante milenios permanecieron ignorantes de su convivencia en el planeta. ${ }^{44}$

- $\quad$ En tercer lugar, la existencia y la confluencia de varios tiempos históricos en una misma espacialidad americana. Se trata de una intertextualidad del tiempo que permite distinguir la sucesión constante y unísona de varios tiempos epocales en una misma sociedad o región. Los desiguales niveles de desarrollo socioeconómicos de las culturas americanas a la llegada de los europeos fueron trastocados y profundizados a partir de los distintos procesos de colonizaciones que establecieron los últimos. Unido al componente geográfico, que influyó en la balcanización de las comunicaciones entre una región y otra, más los intereses específicos que recibieron las regiones latinoamericanas de sus metrópolis, España y Portugal, la heterogeneidad socioeconómica visualizó de manera progresiva la existencia de distintos niveles del decurso del tiempo en una misma espacialidad, permitiendo experimentar la trasgresión constante y real, no imaginada, de un tiempo histórico a otro en la vida cotidiana de nuestros países.

- $\quad$ Por último, la existencia de una exuberante naturaleza americana que es portadora de casi todos los paisajes y los climas universales, inspiró a Carpentier a visualizar similar prodigalidad en las mezclas y copiosas

43 Jaque Le Goff, La civilización del Occidente medieval (Barcelona, España: Editorial Paidós, 1999).

44 Alejo Carpentier, Los pasos perdidos, 44. 
producciones artísticas y literarias de la región, donde periodos de la historia del arte que se sucedieron por siglos consecutivos, como el gótico, el renacimiento, el barroco y el neoclasicismo, por mencionar los fundamentales, se fusionaron en América Latina en unos pocos siglos, generando lo que él mismo gustaba llamar, el barroco americano, no como extrapolación mecánica de ese periodo del arte, sino como el conjunto exuberante y transculturado que es la cultura artística-literaria de América Latina.

Dichos pilotes interpretativos son coordenadas esenciales para comprender cómo evolucionó Latinoamérica desde la llegada de los europeos a fines del $\mathrm{XV}$, «Carpentier no ve lo maravilloso como una abstracción filosófica o estética, sino como reflejo o interpretación de los elementos políticos, históricos, sociales y racionales que representan la totalidad de la realidad hispanoamericana». ${ }^{45}$

Los elementos antes planteados pertenecen por completo al devenir de América Latina desde el inicio de la modernidad, son las estructuras fácticas de su historia; por tanto, no necesitan ser ficcionadas, ni imaginadas al estilo del surrealismo. La subjetividad del autor convierte dicha realidad en maravillosa, mediante sus ojos, su pluma y su discurso escritural. Lo real maravilloso es el resultado de la colisión cultural entre Europa, América y África, que tiene en cuenta el universo mágico-religioso de las culturas nativas y diseminadas en el continente, pero sin necesidad de acudir a la ficción literaria y sí a la subjetividad de todo creador, en este caso, a la provocada por la grandeza de la exuberancia americana. Es un modelo interpretativo pensado en América Latina para explicarla universalmente, sin extrapolaciones mecánicas de la racionalidad europea.

Carpentier, escritor latinoamericano de influencias europeas, postuló con lo real maravilloso un modelo explicativo de la identidad continental expuesto desde los cánones de la literatura occidental, de allí el hecho de la aceptación y el interés por sus obras en Europa. Explicó a Occidente la realidad americana desde códigos históricos latinoamericanos. Al estilo granmsciano, no fue un traductor literal de la América Latina a Occidente, sino un traductor interpretativo de la historia de América Latina desde la universalidad cultural.

Tan útil es su modelo interpretativo que a no pocos científicos sociales latinoamericanos le permitiría distinguir mucho mejor la evolución histórica y cotidiana del tiempo continental desde sus quehaceres profesionales, e incluso en sus vidas cotidianas. Por ejemplo, todavía causa magnífico asombro ver esa guerra del tiempo carpenteriana al encontrar hoy comunidades nacionales y regionales que viven en la era digital, acompañados de cuantos artefactos tecnológicos

45 Branka Kalenić Ramšak, «El realismo mágico, lo real-maravilloso y el surrealismo: una estética parecida», Revista Verba Hispánica, vol. 1, n. ${ }^{\circ}$ (1991): 30, doi: https://doi.org/10.4312/vh.1.1.27-34. 
pueden acumular, pero con valores y conceptos de vida cotidiana de hace más de un siglo, también con léxicos ya en desusos en otras partes del continente sin percibirlo en lo absoluto.

Aprehender esa intertextualidad temporal permite explicarnos también, porqué hay gremios de historiadores que viven en diferentes tiempos carpenterianos con sus consecuentes atrasos o actualizaciones metodológicas, historiográficas y conceptuales. Así, en pleno 2019, existen científicos sociales que no manejan del todo conceptos como interdisciplinariedad, multidisciplinariedad o historia total, procedentes de la historiografía francesa, específicamente, de la obra de Fernand Braudel. Sus tesis, expuestas en su clásica obra de 1949, El Mediterráneo y el mundo mediterráneo en la época de Felipe II, ${ }^{46}$ fueron asimiladas por historiografías como la mexicana y la brasileña desde los años sesenta y en países caribeños, como Cuba, desde finales de los ochenta e inicios de los noventa del pasado siglo.

Cuando un historiador es consciente de ese decurso inconsciente del tiempo y lo interrelaciona con los hechos históricos y la organización social dada, transita a la condición de pensador social. Consciente de ese modelo de interpretación, Carpentier, en voz del protagonista de Los pasos perdidos, aspira a ser un historiador de tal naturaleza, «Hay mañana en que quisiera ser naturalista, geólogo, etnógrafo, botánico, historiador, para comprenderlo todo, anotarlo todo, explicar en lo posible». ${ }^{47} \mathrm{~A}$ su vez, la transculturación carpenteriana llegó a invertir sus aportaciones de un continente al otro. Si bien Fernando Ortiz proyectó su concepto a partir de las mezclas culturales en tierras americanas de Europa y África, Carpentier pudo comprender que la interculturalidad americana también podía servir para interpretar las mezclas culturales que en Europa se sucedieron después de comenzada la modernidad. No como una fórmula, sino como una experiencia histórica. En su novela Concierto barroco (1974), muestra cómo la música transculturada latinoamericana influenció en la europea en el concierto final de la obra, fruto de los diálogos culturales entre Vivaldi, Händel y el protagonista Filomeno.

Lo real maravilloso es la literaturización de la historia de América Latina a partir del inicio de la modernidad capitalista. Cuando Monique Nomo se refirió a El reino de este mundo, base programática de la obra carpenteriana, dijo que, «Lo singular del libro es, quizás, el enfrentamiento de dos perspectivas: una, europea y racionalista; y otra, americana y mítica». ${ }^{48}$ Pero lo real maravilloso no es mítica sin racionalidad, es una racionalidad con su mitología propia dentro del conjunto de la cultura universal.

46 Fernand Braudel, El Mediterráneo y el mundo mediterráneo en la época de Felipe II (Madrid, España: Fondo de Cultura Económica, 2011).

47 Alejo Carpentier, Los pasos perdidos, 133.

48 Nomo Ngamba, 110. 
Es posible que al no ser pensado con la lógica que sostiene la hegemonía cultural en América Latina desde el siglo XVI, todavía se le considera como parte de una perspectiva mítica; pero, ¿por qué América Latina no puede poseer su racionalidad y tiene que ser entendida solo con la racionalidad del dominador?, y ¿será que la racionalidad europea no sustenta su cultura y antigüedad en una mitología de supersticiones, leyendas, sortilegios, oralidades y seres antropomórficos, como la grecolatina y la medieval?

Lo real maravilloso no es un reclamo, una manera de ilustrar para solo hacer entender, o un deseo de emancipación cultural, es, ante todo, un modelo interpretativo propio de América Latina donde mitología y realidad forman su estructura.

\section{Dos modelos interpretativos, una identidad multicultural}

En tiempos de globalidad histórica y transculturaciones universales, donde los flujos migratorios, las mixturas culturales, demográficas, económicas y comerciales son crecientes, lo real maravilloso y el realismo mágico constituyen alfa y omega para una comprensión cultural de la historia de América Latina en larga duración. Con sus características e influencias propias, ambos modelos permiten analizar de manera transversal la secuencia evolutiva que ha estructurado durante siglos el transcurso latinoamericano.

El universo cultural indígena, antes y después de 1492, puede ser comprendido a través del realismo mágico. Su capacidad para mostrar y explicar el mundo latinoamericano rural y urbano, en imágenes, mitos y leyendas, desde las cosmovisiones antropomórficas de sus religiones, junto a su sentido del tiempo circular al estilo de los ciclos y los calendarios mayas y aztecas, le otorgan una potencialidad notable para el científico social interesado en la historia cultural. Nuestros universos indígenas y sus extensiones espirituales dan vida a una comprensión historicista desde el realismo mágico; sin los primeros, poco sustento tendría el último.

El segundo realismo, del postboom, tampoco ha dejado de tributar a la conformación de una cultura regional. Desde la literatura, sus prolongaciones a otras manifestaciones, como el cine, crean y recrean el tejido histórico del continente.

De igual modo lo real maravilloso fija sus puntos interpretativos en una evolución fáctica engarzada con la historia universal que, desde la llegada de los europeos a fines del siglo XIV y el inicio de la colonización, con las primeras décadas del XVI, encuentra sus mejores asideros analíticos en las emigraciones africanas y de otras partes del mundo, en los amplios y ricos procesos de mestizajes culturales, en la diferencia de temporalidades que marca la vida latinoamericana y, por último, en la exuberante cultura continental de carácter ecléctico conformadora de un barroquismo singular.

Lo real maravilloso es una reivindicación espiritual y fáctica del mundo colonial frente a Occidente y su racionalidad colonizadora. Es nuestra propia 
comprensión sobre nosotros mismos. Construida desde vínculos históricos con esa occidentalidad hegemónica, articula un discurso sin pleitesías, lisonjas ni extrapolaciones estéticas, que muestra y demuestra la grandeza latinoamericana.

Al utilizar una o ambas categorías literarias como modelos interpretativos de nuestras sociedades, tendremos frente a nosotros un horizonte histórico de siglos secuenciales; o, por el contrario, momentos, hechos precisos o procesos culturales que deseemos investigar de la historia americana. Su devenir cultural no es más que el conjunto de su universalidad relacional, cuya variedad artística y literaria permite comprender más aún sus sociedades. Si bien la geografía y los desiguales procesos históricos nacionales contribuyeron a la balcanización de nuestras sociedades, precisamente de su heterogeneidad cultural nace su fortaleza universal.

Miguel A. Asturias y Alejo Carpentier relataron sus diferentes visiones de América Latina a partir de sus respectivas interpretaciones históricas. Lo que equivale a decir que sus aportaciones literarias son discursos narrativos estructurados desde miradas autóctonas. En las páginas anteriores hemos tratado de validar que ambas contribuciones son, a su vez, modelos de interpretación para el historiador de la cultura u otros estudiosos de Latinoamérica.

Puede augurarse, además, que, en las nuevas fuentes para el trabajo del científico social, las huellas del realismo y lo real no dejarán de impregnarse en sus contenidos, como así lo demuestran obras audiovisuales, pictóricas, musicales y dramatúrgicas de la contemporaneidad.

Nuestra historia cultural es una producción de orígenes indigenistas, africanos y europeos entrelazada por un variadísimo sistema de relaciones sociales que se conectan con áreas culturales de la historia universal, como la política, la economía, la demografía y otras, para conformar el entramado organizativo de cada sociedad y nación. Su universalidad relacional posee un doble carácter, como pluralidad de unicidades sociales, y a su vez, como producción artística-literaria de reconocido y ascendente protagonismo internacional. Es una dualidad que nos inquieta para hacernos a cada instante la pregunta inicial de estas páginas, pero también en sentido opuesto para continuar conociendo nuestra historia, ¿qué lugar ocupa la historia universal en América?

\section{Bibliografía}

Acanda, Jorge Luis. Sociedad civil y hegemonía. La Habana, Cuba: Centro de Investigación y Desarrollo de la Cultura Cubana, 2002.

Allende, Isabel. La casa de los espiritus. Santiago de Chile, Chile: Editorial Sudamericana, 1982.

Álvarez Pitaluga, Antonio. «La historia en la novela cubana del siglo XIX». Revista Upsalón (Cuba) n. 2 (2004); 56-59. 
. La isla gigante. Cuba y su cultura contemporánea. Principales vínculos con América Latina 1959-2016. San José, Costa Rica: Editorial Arlequín, 2018.

Asturias, Miguel Ángel. El señor Presidente. Barcelona, España: Ediciones Atalaya, 1995.

. Hombres de maiz. Buenos Aires, Argentina: Editorial Losada, 1949.

Barboza Núñez, Esteban. Litorales imaginados, dominios construidos: desarrollo turístico de sol y playa y discurso colonial en Guanacaste. Tesis doctoral, Universidad Nacional de Costa Rica, Costa Rica, 2019.

Bethell, Leslie. «La independencia de Brasil», En Historia de América Latina.

Tomo 5, editado por Leslie Bethell. Barcelona: Cambridge: University Press, 2000.

Braudel, Fernand. El mediterráneo y el mundo mediterráneo en la época de Felipe II. Madrid, España: Fondo de Cultura Económica, 2011.

Carpentier, Alejo. La música en Cuba. México: Fondo de Cultura Económica, 1946. . El reino de este mundo. Ciudad de México: México, Editorial, 1949. . Los pasos perdidos. La Habana, Cuba: Editorial Letras Cubanas, 2005. . El siglo de las luces. La Habana, Cuba: Editorial Letras Cubanas, 1975. . Concierto barroco. La Habana, Cuba: Editorial Letras Cubanas, 2015.

Centeno, Daniel. «Las formas de lo inverosímil», citado por Esther Magar. https:// relatosmagar.com/diferencia-entre-realismo-magico-y-real-maravilloso/.

De Feo, Fulvia María. «La huella de Fernando Ortiz en la cosmovisión histórica de Alejo Carpentier». Revista de la Biblioteca Nacional José Martí, n. ${ }^{\circ}$ 2 (2016): 56-65. http://revistas.bnjm.cu/index.php/revista-bncjm/article/ view/3816.

Donahue, F. «Miguel Ángel Asturias: su trayectoria literaria», Cuadernos Hispanoamericanos, (España), $\mathrm{n}^{\circ} .68$ (1965).

Esquivel, Laura. Como agua para chocolate. Ciudad de México: México, Editorial Planeta, 1989.

Fernández Retamar, Roberto. Todo Calibán. La Habana, Cuba: Casa editorial ALBA, 2012.

García, Gabriel. Cien años de soledad. Madrid, España: Editorial Planeta, 1967.

Guerra, Sergio. Nueva historia mínima de América Latina. Biografia de un continente. Santo Domingo, República Dominicana: Archivos de La Nación, 2015.

González-Ortega, Nelson. «La novela latinoamericana de fines del siglo XX: 1967-1999. Hacia una tipología de sus discursos» (s. f.). https://www. hf.uio.no/ilos/tjenester/kunnskap/sprak/nettsprak/spansk/lesesal/innforingspansklitteratur/tekster/nelsonmoderna.pdf.

Guibert, Rita. «Miguel Ángel Asturias. Entrevista con Rita Guibert», 7 Voces. México: Organización Editorial Novaro, S. A (1974). https://www.literatura.us/miguel/rita.html. 
Hobsbawm, Eric. La era del imperio (1875-1914). Barcelona, España: Editorial Crítica, S. L. 2013.

. Historia del siglo XX. Barcelona, España: Editorial Crítica, S. L., 1994.

Kalenić Ramšak, Branka. «El realismo mágico, lo real-maravilloso y el surrealismo: una estética parecida». Revista Verba Hispánica, vol. 1, n. ${ }^{\circ} 1$ (1991): 27-34. doi: https://doi.org/10.4312/vh.1.1.27-34.

Le Goff, Jaque. La civilización del Occidente medieval. Barcelona, España: Editorial Paidós, 1999.

Lezama, José. Paradiso. La Habana, Cuba: Ediciones Unión, 1966.

Martí, José. «Nuestra América». Revista La Revista Ilustrada de Nueva York (Estados Unidos, 1891).

Martínez Azaña, Manuel y Claude Mie. «Entrevista con Miguel Ángel Asturias, Premio Nobel». Revista Bulletin Hispanique (Francia), vol. 70, n. ${ }^{\circ}$ 1-2 (1968): 134-139.

Morgan, Kenneth. Cuatro siglos de esclavitud trasatlántica. Barcelona, España: Editorial Crítica, 2017.

Moro, Tomás. Utopía. Madrid, España: Círculo de Bellas Artes, 2011.

Nomo Ngamba, Monique. «El "Realismo mágico" y lo "Real maravilloso": dos visiones de la literatura postcolonial», Intercambio/Échange, n. $^{\circ} 1$ (2016): 106-116. https://repositori.udl.cat/bitstream/handle/10459.1/58545/intech_a2016n1p106.pdf? sequence $=1$ \&isAllowed $=\mathrm{y}$.

Ortiz, Fernando. Contrapunteo cubano del tabaco y el azúcar. La Habana, Cuba: Editorial de ciencias sociales, 1983.

. Revolución, hegemonía y poder. Cuba 1895-1898. La Habana, Cuba: Fundación Fernando Ortiz.

Sarmiento, Domingo. Civilización i barbarie. Vida de Juan Faustino Quiroga. Santiago de Chile: Imprenta el Progreso, 1845.

Spengler, Oswald. La decadencia de Occidente. Madrid, España: Editorial Espasa-Cape. S. A., 1966.

Todorov, Tzvetan. La conquista de América. La cuestión del otro. Ciudad de México, México: Siglo Veintiuno Editores, 1998.

Volpi, Jorge. «El fin de la narrativa latinoamericana». Revista de Crítica Literaria Latinoamericana, n. 59 (enero-junio, 2004): 33-42. https://as.tufts. edu/romancestudies/rcll/numero59.htm\#numeros.

Weber, Max. Economía y sociedad. Ciudad de México, México: Fondo de Cultura Económica, 1997. 
